\title{
Improvement of Family Relationships as a Social Duty
}

\author{
Hamid Aran ${ }^{1}$, Maryam Nayebkabir ${ }^{1}$ \\ ${ }^{1}$ Baku State University, Baku, Azarbaijan \\ Correspondence: Maryam Nayebkabir, Baku State University, Baku, Azarbaijan.
}

Received: April 16, 2017

doi:10.11114/smc.v5i1.2437

Accepted: May 14, $2017 \quad$ Online Published: May 23, 2017

URL: https://doi.org/10.11114/smc.v5i1.2437

\begin{abstract}
The present research is aimed to study the improvement of family relationships as a social duty. To achieve this goal, the descriptive-analytical method was used. Family relationship is one of the most important factors whose negative effects on society can be investigated and studied. Family is one of the most fundamental institutions of any society about which many experts and specialists have thought and speculated. These experts have searched for the origin of all abnormalities and misbehaviors in the family. In fact, no society can claim health unless it enjoys a healthy family. The present research is a theoretical research based on library studies. It attempts to study the status of family relationships in Iran, the factors affecting the formation and evolution of family relationships, the effect of progress and modernization on family relationships, and the causes of family relationships looseness.
\end{abstract}

Keywords: family relationships, progress, modernization

\section{Problem Presentation}

Religion and family are among those social institutions which are considered as holy or sacred and, thus, have transcendental status and position for individuals and society (Seif, 1368). Family is, indeed, a part of social system which is not only influenced by other social institutions but it also provides the ground for changes in these institutions (Bills \& Parsons, 1998: 109). Generally, all the divine religions emphasize on the sacredness and sanctity and respectability of the family institution and include some rules and regulations for adjusting the family relationships. Bertalanffy, in his systems theory, considers family as a whole comprised of constituents. Goldenberg (2000) believes that family is an environment in which the couple and the children have close interaction with each other. Besides, creating strong and effective emotional relationship, in the family environment, with the main partner of life and spouse can meet a large part of the mental and emotional needs. Improving the family relationships can have determinative effects on the increase of quality in all parts of life and can also be regarded as an effective factor in achieving more successes and accomplishments.

Furthermore, since family is one of the most fundamental positions for human beings' presence in life, it is considered as one of the most important centers of human training and breeding. In order to normalize the relationships in such center, its first member (wife and husband) must have necessary skills for creating healthy relationships and keeping and protecting the family against any problem which can expose it to risk. Islam, with its specific legislation discipline and system, tries to keep the family and strengthen its pillars and foundations based on ethical principles and values, because matrimonial connection and marriage is an instinctive issue which, in the first step, doesn't need any specific training and stimulant or incentive, but continuity of this connection and having proper and sustainable relationships, which can lead to stability and durance of family, requires training and education (Motahhari, 1386: 229). On this basis, regarding the fact that the family relationships and especially the relationships between spouses are among the most important and determinative parts of human relationships which can affect all the parts and areas of our lives, the present research is aimed to investigate and study the improvement of family relationships as an important social duty.

\subsection{Research Background (Review of Literature)}

Azizollah Aghababaei and Mahboubeh Bagheri performed a research titled internet and family relationships. Their results showed that the amount of using internet affects the variables such as reduction of daily activities, parents' distrust in children, reduction of face to face connections, social isolation, and reduction of social activities in $\mathrm{p}<0.05$ level.

Also Seyyed Ahmad Ahmadi and Parvin Shamaeizadeh performed a study on the effect of disciplined training of 
parents on the family relationships and academic achievement of female high school students in Falavarjan city. Their findings demonstrated that disciplined training of the parents, in 0.05 level, positively affects the mutual relationships and micro-scales of family relationships, family correlation and adaptability, and academic achievement of the children.

Zargham Ghanbarpour et al, too, have performed a research titled studying and comparison of family relationships in academically successful and unsuccessful students. The research findings showed that the family relationships which affect the students' academic success and failure are intertwined factors. Results showed that the family members' relationships, the parents' responsible behavior toward children, and relationships and interaction of parents with each other can affect the students' academic failure and success.

\subsection{Research Method}

The information gathering method in the present research is of library type so that the researcher has obtained the required information from review of books, journals, magazines, and so on. The information gathered through note-taking (fiche-making) will be analyzed.

\subsection{Family Relationships}

Family is the center of a society and a focal point for keeping and maintaining traditions, rituals, customs, habits, and also a center for formation of feelings and emotions. On this basis, family is one of the most important social institutions in human societies and, in terms of social behaviors, it has vast effects. Formation of a family is originated from marriage (Sadeghi Ardestani, Bita: 18). Formation of family in Islam is a vital issue and a transcendental and excelled plan which, despite being realized based on Quranic, religious, and traditional rules and regulations, its motifs are institutionalized in human beings in form of instinct, affection, emotion, and mutual eagerness of spouses toward the God's divine wills and determinations. Creation of serenity and cordiality as a consequence of marriage is one of the signs of God's grace and favor (kindness). In addition to the materialistic and natural aspect of marriage, which is a reasonable and ordinary social issue, what gives greatness and sanctity to marriage is the divine reward and humane aspect, which is formed after formation of family because such connection and joining results in divine grace and blessing (Al-Horr-Al-Ameli, vol.15, 1412: 267). After marriage the family environment is developed and finds numerous functions. Attempting to strengthen the family's fundaments is the most principal constituent of the society and its constructive and effective role in society is regarded as one of the long-term solutions introduced by thinkers and programmers (policy makers) of the society (Sadeghi Ardestani, Bita: 18).

\subsection{Family Relationships in Iran}

The main form of family in ancient Iran has been an extensive and vast one where the family members lived in one place and under protectorate and guardianship of the head of the family (Bartlameh, 1344: 17). Family gradually changed from an extensive form to a core one. In that era, marriage of the princesses and the governing class was done with aims such as marrying individual from the same class and same level, increasing wealth, absorbing tribal supports, and basically achieving stability and sustainability of the government and other political objectives (Hejazi, 1370). The Iranians regarded matrimony (marriage) as one of their religious duties and to the extent they emphasized on matrimony, the severely disagreed adultery (Alavi, 1378: 53-54). Besides regarding the marriage as a sacred issue, Iranians (Zoroastrianism followers) didn't admire divorce and according to Zoroastrianism a man shouldn't cut his matrimonial relationship with his wife (Ravandi, 1383: 640). By collapse of Sassanid kingdom in 651 BC (31 Lunar Hijri) and Islam's entering to Iran, great changes occur in the Iranian family structure under the effect of Islamic instructions. Since Islam has fundaments and principles for any aspect of human life, it enacted some rules, regulations, and principles for the Muslims' lives. Some of these regulated principles are: necessity of being Muslim for both spouses, impermissibility of polygamy, husband's incumbency to pay wife's Nafaqe (life's expenditures), wife's obligation to be obedient to her the husband, acknowledging the wife's economic independence through acknowledging her heredity and ownership, and so on. Following and observing these principles caused that the Muslim Iranians' lives be formed based on the Islamic rules and also led to some outstanding changes in the Iranian families' conditions and status (Asefi, 1352).

In Qajar society there was a short interval between the girls' childhood and marriage. Girls often married at the age of 13 or 15 and practically entered the family life as an independent fundament. In reality, factors such as economic problems, common social beliefs, etc, had notably influenced the increase of early marriages (Delrish, 1375: 23). After the Islamic revolution, the family relationships and sex-related roles in the society underwent remarkable changes. The Islamic Revolution in Iran in 1375 was a turning point in the history of the Iranian women's participation in the public scene of the society, particularly in the political scene (Bahramitash \& Hooglund, 2011: 2). After the victory of the Islamic Revolution, Imam Khomeini introduced the religion as the axis and center of the politics and society, and his revolutionary interpretation of Islam played a key role in formation of the main rules and principal governmental policies (Sadeghi, 2008). In fact, the Islamic Revolution introduced the issue of women as an important problem not 
only for the oppositions of the new government but also for the advocates of the Revolution and the men and women present in the government body (Najmabadi, 1998). In introducing an ideal example of woman in the post-Revolution society, the life and personality of Fatimah Zahra, Khadijah, and Zeinab (Peace Be Upon Them) have been always considered important in the new cultural policy. With regard to such examples, women's active presence both in family and society was elaborated as a value in the new system although the main emphasis was on their maternal role inside the family. Many of the traditional and religious families, due to the non-Islamic approach of the former government, avoided allowing the girls to enter high schools and universities; however, after the revolution, with regard to the trust and belief in Imam Khomeini's statements and doctrine, families encouraged the girls and women to take presence and participate in the social scene of the society for education and working. Another change in the family relationships in the post-Revolution society was presence and participation of Muslim women in the public media specifically in radio and television. In the early post-Revolution days, Imam Khomeini introduced radio and television as a public university and emphasized that "we are not opponent to radio, we are opponent to reprobation. We are not opponent to television, we are opponent to whatever helping the aliens to prevent our youths' progress and whatever causes we lose our human forces." (Sahifeh Noor, Vol.6, p15; 1382). Thereby, women, specifically the Muslim revolutionary women, found the opportunity to take presence and participate in radio and television and gradually enter this forbidden zone.

\subsection{Effective Factors in the Formation and Evolution of Family Relationships}

The most important factors which strengthen the family foundation, set up family, and keep the connection between the family members are as follows:

\section{Nature}

Humans are naturally collective beings and thus always escape from isolation and loneliness. Before building a family, a man has vigorous dependence on the family where he has been born but in the first suitable opportunity he forms a family and remains faithful and loyal to it. Moreover, sense of belonging to the people and environment, that a man has been accustomed to them, naturally makes him loyal and committed. Despite seeming an acquired thing, this is an attraction from the inside or in other words an inner attraction (Seif, 1386: 21).

\section{Ethic}

Ethic includes "habit, humanity, temper, and religion". Ghazali, too, believes that "ethic is indeed correction and adornment of the triple forces of thinking, lust, and wrath." He believes that ethic is a configuration penetrated in the soul which make the man to behave easily, simply, and without thinking and speculating. This state paves the ground for issuance of desirable and good acts and avoidance from undesirable and bad acts. Based on these two and other definitions of ethic, it is clear that the relationship between ethic and family is an essential and direct relationship because, anywhere other than the safe and secure and constructive environment of a family, no human being will be able to achieve and acquire awareness and perfection and resolve and remove the deficiencies and defects of his souls and behavior (Taghavi, 1374: 192).

\section{Sharia (Religion)}

The role of different religions in organizing and guiding the human life, specifically in social relationships, has been a fundamental, credible, and sustainable role. Determining behavioral regulations and criteria, divine religions, in addition to correcting the human relationships, have taught human beings the appropriate family and social manners and etiquettes. Without any exception, all the divine religions have accurate rules and regulations for adjusting the family relationships. These rules, in their principal form and without any distortion and falsification, can guarantee peace and serenity in the families because they are based on the human's divine nature; this is why the families of faithful people are more stable and sustainable and have less divorce rate compared to families with less faithfulness and religious beliefs (Ghaemi, 1378: 320).

\section{Meeting Emotional and Sexual Needs}

Free and unrestrained catering of this instinct is absolutely forbidden and prohibited in Islam. The ways to cater and satisfy this instinct are limited to those ways which are based on the human's divine nature and the individual and social interests and expediencies of all human beings; therefore, as the first fundamental step to keep family, the sexual instinct must be satisfied as a natural need through sexual enjoyment from an individual of the opposite sex and homosexuality is prohibited (in Islamic religion terms it is called haraam). Moreover, enjoying sexual pleasure of the opposite sex, too, must be limited to the legal and religious frameworks and regulations (Mesbah Yazdi, 1389: 209).

\section{Vision and Awareness}

Basically, health and stability of a family requires that the family members have social vision, insight, and awareness and also have necessary knowledge for family construction and preventing conflictions and disagreements. 
Undoubtedly an unbridle family is a product of its members' unawareness of the importance of family and its role in their future and destiny. Such unawareness causes that the spouses don't make sufficient effort to keep and maintain their joint life; as a result, factors such as false pride, inopportune and improper expectations, poverty, selfishness, suspicions, and disregarding the spouse's situation and conditions would soon shake the family foundations and make them unstable because the required motivation for keeping life is absent in such families. In such cases, the only solution would be divorce, while many of the family problems are rooted in unawareness of the duties and lack of knowledge about the solutions for making relationships and problem-solving.

\section{Consultation}

One of the features of a stable and balanced family is trying to use consultation in order to achieve agreements in the family. According to the Islamic instructions and teachings, exploiting others' opinions and ideas for problem-solving is the best and the most appropriate method for decision-making. There is no doubt that one of the most important issues in any family is to use consultation for handling the family and solving the problems (Mesbah Yazdi, 1380: 54).

\section{Regarding the Family Members' Rights}

It is evident that all the family members have some rights and duties toward each other. Imam Sajjad (the fourth Imam of Shia Muslims), in his "the rights" treatise, expresses the parents rights on the children as: "the mother's right on you is that you should know that she has born you in such a way that nobody bears anyone else, she has fed you from her soul's extract in such a way that nobody feed anyone else, she has kept and protected you with her ears, eyes, hands, feet, skin, and all her organs and is pleased and satisfied by this protection, she has tolerated many worries, pains, agonies, and troubles to protect you against troubles and disasters, thus you must be thankful to her as much as all her efforts and you must be aware that you can't be thankful to her except by help of the God. But your father's right is that you must know that he is your origin and root, you are like a twig for him and if he wasn't then you wouldn't exist now, so whenever you see something good inside yourself you should know that it is rooted in your father, thus you must thank god as much as that goodness and be thankful to him and know that everything is governed by God." (Harrani, 1387: 461).

As for the duties of each parent toward the whole family, in Quran the God states: "O, you believers, save yourselves and your families from the hellfire whose fuel is men and stones, over it are angels stern and strong, they do not disobey Allah in what He command them, and do as they are commanded." The order of "enjoining good and forbidding wrong" (promotion of virtue \& prevention of vice) is a public order of Islam to all the Muslims, but some other narrations and traditions about the children's right can be interpreted from this verse. The verse indicates that a human has a more important and heavier duty and responsibility toward his wife and children and must attempt, as much as possible, to instruct and train them, prevent them from vices and sins, invite and guide them toward goodness, and should know that meeting only the physical needs in not sufficient (Makarem Shirazi, 1362: 293).

\section{Good Strategy in Economic Affairs and Contentment}

Contentment means being pleased by what you have and by your share of life. In general, one of the main features which can create sense of satisfaction in the family is contentment. Contentment has got vast dimensions one of which is financial and economic contentment. Financial contentment can not only lead to a mental and psychological serenity but it also can have direct effect on adjustment of life expenses and creation of an economic balance. Contentment can make the humans to be pleased by their assets and try to be thankful to God for them (Farjad, 1389: 23).

\subsection{Effect of Progress and Modernization on Family Relationships}

Industrialization and civilization are two processes that have led to new changes in the social and individual life. Some of these changes have had positive effects while some others have negatively affected the families' capital level. The main changes are as follows:

1- Reduction of emotional relationships in family: in the Islamic system of values, creating affectionate relationship among the Muslims has been always emphasized. These recommendations have been more emphasized in families and toward relatives in order to create strengthen the family infrastructure in addition to strengthening the affectionate connection between the spouses (Kafi, Vol.5: 569). Entrance of the western thought and culture shrouded under the mask of modernization and being up-to-date has loosen the family foundations and infrastructures and propagation of materialistic and utilitarian values. It has weakened the humane and spiritual aspects of the relationships more than ever and has changed the relationships to strict and machine-like connections; the consequence of such kind of relationships is increase of depression and crimes in addition to the sense of psychological insecurity among the children in their childhood and adolescence.

2- Increase of divorce: in Iran, according to the statistics, the growth of divorce rate is evident. One of the most important reasons for such growth is the effect of modernity on culture, which results in the crisis of cultural and 
religious values. In fact, this effect has faded the religious values and, consequently, resulted in the crisis of divorce growth. According to the experts, in such conditions, the values of the society are founded on hedonism, instant enjoyment, individual pragmatism, utilitarianism, materialism, and instrumentalism; therefore, the individuals think merely about enjoyment and regard only their own advantages and see everything from a materialistic perspective. In such conditions, the humans' relationships have no spiritual aspect and become extremely fragile and vulnerable; the matrimonial relationships are not excepted and thus the divorce rate is increasingly growing.

3- Increase of using media and entrance of virtual networks into families: another change in today families is the increase of using media and entrance of virtual spaces such as internet and satellite into the families which, in addition to reducing the emotional relationships, plays an important and principal role in forming or strengthening the thoughts, opinions, and attitudes of the society and engages the individuals with themselves and prevent them from interaction with others.

4- Increase of marriage age and its effect on reduction of reproduction: in recent years, the average age of marriage has increased in most of the countries so that people marry in higher ages and, evidently, will have children in older ages. Increase of the marriage age is another consequence of modernity because when welfare-seeking, which is one of the fundamental principles and doctrines of modernism, penetrates into the society, then all the criteria of choosing spouse will be founded and indexed based on providing perfect welfare and wealth at the starting point of marriage and providing all the necessary and unnecessary facilities. On this basis, focusing on having an independent house, having notable wealth, etc, become the main requisites of marriage for girls and families; therefore, since only few young boys ca provide such facilities at the beginning of life, the age of marriage increases more and more and goes up.

5- Change in the method of spouse-choosing and marriage customs and traditions: the customs and traditions of choosing spouse and marriage are among the main targets of modernity attacks. The effective role of elders and parents in choosing a spouse for their children, holding marriage ceremonies, observing and regarding the traditions and regulations of this area, and other relatives' participation in this tradition, was very outstanding in past years, but today the effect of individualism is very notable and observable in decisions related to marriage and spouse choosing. Due to industrialization, civilization, and modernization, the children have gained acquired more independence and control on choosing spouse and deciding the marriage time and their marriages have got new faces and new forms. Spouse choosing, which was previously done through suggestion of parents and elders or intermediation of other people, is today done through acquaintance of girls and boys in workplaces, universities, or even on internet and virtual spaces and chat rooms, and sometimes even the opinion of parents is disregarded (Chris, 1383: 54).

\subsection{Reasons for Loosening of Family Relationships}

Some reasons and factors which cause undesirable problems in families are:

\section{1- Lack of recognition and awareness of matrimonial life principles}

In some families, lack of spouses' recognition of each other's characteristics, unawareness of marriage objectives, injustices, prejudgments, deceptions, lack of responsibility, and disregarding ethical principles loosen the family foundations. The most important factor which hurts the families is the lack of recognition of marriage objectives and divergence or deviation from these objectives. Which direction or path will be followed by a couple who have forgotten or haven't yet recognized the goals and objectives of marriage and family construction? Which method or instrument will be chosen by them for achieving which objective? In order to solve this problem, you should improve and upgrade your skills and knowledge of spouse-treatment principles, because through these skills you can protect and maintain the balance and health of your family.

\section{2- Loosening of religious beliefs}

Perhaps the most important factor which threatens the family foundation is loosening and enervation of religious beliefs and ethical principles and lack of spirituality. Whenever spouses ignore the God in their relationships and behave each other as if God is not present, they indeed enervate their family's foundation and lead it toward destruction. Thus, under such circumstances, the relationships will be very fragile and unstable and will be broken and ruptured as soon as a particular situation such as poverty, disease, or aging happens.

\section{3- Dishonesty and deception}

The essence of a healthy relationship between spouses is honesty and truthfulness. Honesty founds trust and confidence. A man or woman who is not honest and tries to continue the life with false promises enervates the close and intimate relationships among the family members. Will a man or woman who is far from realities and lives in illusions have a successful matrimonial life? Sometimes concealing the truths (secretiveness) and deception and seduction (deceitfulness) can enervate and loosen the family foundations and hurt the spouses' relationships. 


\section{4- Disregarding the needs of the spouse and children}

Successful couples are those ones who attempt to satisfy and meet their spouses' needs thus anybody has a duty to recognize the spouse's mental and physical needs and try to meet them. Meeting the needs through appropriate methods will result in comprehensive mental and psychological security of the couples and, consequently, the health of the family. For example, any human being needs security, affection, attention, and respect; therefore, if these needs are not met, then the individual will feel a sense of insecurity and thus the family's psychological health will be disordered.

It is evident that considering the spouse's needs is not limited to the matrimonial needs. So respect and acceptance, having kind and affectionate view toward each other, being with each other, participating in joint activities, and doing some other similar activities are signs of regarding and paying attention to the spouse's needs (Ghazanfari, 1389: 43).

\section{5- Inopportune intervention of relatives}

Intervention of other people such as relatives or spouses' parents can intensify the spouses' disagreements and problems and eventually result in their divorce. The wife or husband, especially at the beginning of the matrimonial life, are clumsily misguided and sometimes stimulated by other people; this, in long term, can threaten the family's health and manifest its effect as divorce. Divorce is considered as one of the most sensitive, complicated, and confidential occurrences in anybody's life and thus must be studies as a multi-factor phenomenon.

\section{6- Revenging and carping}

Revenging, carping, and reproaching are among the most important factors which can hurt the family and the couples' relationships. Continuous repetition of offenses, resentments, weak points, and failures can threaten and destroy the structure of matrimonial relationships. Thus, in case of disagreements, you should try to forgive your spouse and see his/her positive and strong points; besides, you must try to ignore some of his/her behaviors and sayings. In other words, you shouldn't make a mountain out of molehills.

\section{7- Luxuriousness}

Materialism is one of the manifestations of mammonism and luxuriousness is the most outstanding sign of materialism. When materialism reaches its peak and changes into mammonism, it can result in various lapses and faults and prevent the humans from achieving perfection. Luxuriousness causes that an individual's consumption exceeds his production; therefore, in a more extensive perspective, a society that is straying and going toward the wrong way of luxuriousness will be a consumerist society. This means that by consuming most of the resources and assets, the society will no longer have sufficient power for production and investment (Chris, 1383: 65).

\section{Conclusion}

There are numerous and various factors which influence the social security and serenity. Some of these factors are social while some others are individual. Family relationships are among the most important factors whose negative effects on the society's serenity and security can be investigated and studied. Family is one of most fundamental institutions in any society that many experts have speculated about it and have searched for the origins and roots of all the abnormalities and deviations in the families. In fact, no society can claim being healthy except that it has got healthy families. Since one of the most fundamental positions for humans' presence is the family, which is considered the most important center for training and breeding the human beings, thus the spouses must have the required skills for creating healthy relationships and protecting the family's foundation against any threat and danger. Having a specific regulating system and discipline, Islam religion has always attempted to keep the family and strengthen its foundations based on the ethical principles and values, because the matrimonial connection and marriage is basically instinctive and thus, in the first step, it doesn't need special stimulants and trainings but continuity of this connection and having sustainable and appropriate relationships which can lead to the family's stability require training and instructions (Motahhari, 1386: 229). On this basis, since family relationships, specifically between the spouses, are of the most determinative and important human relationships which can influence all the aspects of life, thus the present research (as a theoretical research which is based on library studies) is aimed to study the improvement of family relationships as a social duty. To achieve this, we have investigated and studied the status of family relationships in Iran, the factors which affect the formation and perfection (evolution) of the family relationships, the effects of progress and modernization on the family relationships, and the reasons of loosening and enervation of the family relationships.

\section{References}

Agha, B. A. Bagheri, Mahboubeh; internet and family relationships.

Alavi, H. (1378). Woman in ancient Iran; Tehran; Hirmand.

Asefi, A. (1352). Family and training in Iran; Tehran, National Association of Parents \& Instructors publications. 
Bahramitash, R., \& Hooglund, E. (2011). Introduction. Gender in Contemporary Iran: Pushing the Boundaries. R. Bahramitash and E. Hooglund. Oxon, Routledge, 1-10.

Bartlameh, C. (1344). Woman in Sassanid Laws; translated by Nasereddin Sahebzamani; Tehran; Ataei.

Chris, E. (1383). Life Skills; translated by Shahram Mohammad Khani; Tehran; Espand Honar.

Delrish, B. (1375). Woman in Qajar era; Bija; The Islamic Promotion Organization.

Farjad, M. H. (1389). Social pathology of family conflictions and divorce; Qods publications.

Ghaemi, A. (1378). Creation of family in Islam; Tehran; Amiri publications; $10^{\text {th }}$ edition; 1378, 320.

Ghanbarpour, A. Z., Farahbakhsh, K., \& Esmaeili, M. (1391), Investigation and comparison of academically successful and unsuccessful students; quarterly magazine of family researches, 337-353.

Ghazanfari, F. (1389). Pattern of family relationships and family's violence toward women in Lorestan province; Journal of Psychological Health Principles, 5-48.

Goldenberg, E., \& Goldenberg, H. (1387). Family-therapy; translated by Hossein Shahi Baravati \& S. Naghshbandi \& E. Arjmand; $4^{\text {th }}$ edition; Tehran; Ravan publications.

Harrani, A. M. (1387). Tohaf-al-Oghul; translated by Sadeh Hassanzadeh; Qom; Ale Ali.

Hejazi, B. (1370). Woman in history; Bija, Shahrab.

Horr, A., Mohammad, B. H. (1386). Etiquette in Shia Imams' point of view (a selection of Vasael-al-Shia); translated by Mohammad Ali Farabi \& Yasub Abbasi Ali Kamar; Mashhad; Islamic Researches Foundation.

Makarem, S. N. (1362). Tafsir Nemooneh; Qom; Dar-al-Kotob-Al-Eslamiah, 2.

Mesbah, Y., \& Mohammad, T. (1380). A Pamphlet of laws \& politics In Quran.

Motaharri, M. (1386). The System of woman rights in Islam; Farhang publications.

Najmabadi, A. (1998). Feminism in an Islamic Republic: Years of Hardship, Years of Growth. Islam, Gender and Social Change. Y. Y. Haddad and J. L. Esposito. New York, Oxford University Press: 59-84.

Parsons, T. (1998). Family Socialization and interaction process, printed and bounded in grate britain.

Rahimi, G. H. (1369). Islamic ethics; Ma'aref publications.

Ravandi, M. (1384). Social history of Iran; Tehran; Negah publications.

Sadeghi, A. A. Ethics in family; vol.3; Bita; Hafez Novin publications; Tehran.

Sadeghi, F. (2008). Fundamentalism, Gender and the Discourse of Veiling (Hijab) in Contemporary Iran Culture and Society in Iran, Living with Globalization and the Islamic State. M. Semati. New York, Rutledge.

Seif, S. (1368). Theory of family growth; Tehran; Alzahra University publications.

Shamaeizadeh, P. A., \& Seyyed, A. (1387). The effect of disciplined education of parents on family relationships and academic achievement of female high school students in Falavarjan city; a research on educational sciences; Islamic Azad university, Khoorasegan (Isfahan) branch, 17\&18, 165-186.

Taghavi, N. (1374). Sociology of family; Tehran; Payam Nour University; $1^{\text {st }}$ edition.

\section{Copyrights}

Copyright for this article is retained by the author(s), with first publication rights granted to the journal.

This is an open-access article distributed under the terms and conditions of the Creative Commons Attribution license which permits unrestricted use, distribution, and reproduction in any medium, provided the original work is properly cited. 